\title{
COMPUTATION OF SUCCESSIVE ABSORPTION RATE IN BRAIN USING SIMULATION OF ELECTROMAGNETIC RADIATION - FDTD METHOD
}

\author{
C. K. Smitha ${ }^{1}$, N. K. Narayanan ${ }^{2}$ \\ ${ }^{1}$ Department of Electronics \& Instrumentation Engineering, College of Engineering, Vadakara, Kerala- 673105, \\ smithack@cev.ac.in \\ ${ }^{2}$ Department of Information Technology, Kannur University, Kerala- 670567, \\ nknarayanan@gmail.com
}

\begin{abstract}
Electromagnetic absorption in brain due to mobile phone radiation is measured as Successive Absorption Rate (SAR). The SAR can be computed in terms of magnitude of Electromagnetic radiation (EMR) in brain. The magnitude of EMR is simulated using Finite Difference Time Division (FDTD) method since it could not be measured directly. FDTD method is a numeric method in time domain, obtained from the Maxwell equations in differential mode. Generally the mobile phones have an output power less than $1 \mathrm{~W}$ and emit radiations ranges from $900 \mathrm{MHz}$ to $2200 \mathrm{MHz}$. So we simulate the experiment for two frequencies (900MHz and $1800 \mathrm{MHz}$ ) with two powers $(0.6 \mathrm{Wand} 1.2 \mathrm{~W})$. The value of SAR at $900 \mathrm{MHz}$ and $1800 \mathrm{MHz}$ d for input powers of $0.6 \mathrm{~W}$ and $1.2 \mathrm{~W}$ are computed using this method.
\end{abstract}

Keywords: Mobile Phone Radiation, SAR, FDTD.

\section{INTRODUCTION}

Mobile phones generate a modulated radio frequency electromagnetic field (RF-EMF), which is a form of nonionizing radiation. Electromagnetic radiation can be classified into ionizing radiation and non-ionizing radiation, based on whether it is capable of ionizing atoms and breaking chemical bonds. Electromagnetic fields induce an electric field and a current in the body. A strong electric field, depending on its frequency, might warm up tissues or disturb the neuronal functions. Two types of effects are produced in human tissues due to radiation, thermal and non thermal. Non thermal effects include changes in molecular and cellular level. Thermal effects produced by radiation are measured based on energy absorption of the tissue. The rate at which radiation is absorbed by the human body is measured by the Specific Absorption Rate (SAR) [9-11]. SAR is used as a measure of absorption of non ionizing electromagnetic radiation.

The SAR can be estimated by i) Insertion of micro antennas within the tissue which detect the electric field. ii) Insertion of miniature thermal probe to measure temperature. iii) Numerical modeling like FDTD which simulate the spatial distribution of radiation within the body. FDTD is a grid -based differential numerical analysis technique used for modelling computational electrodynamics. FDTD solutions can cover up a wide range of frequencies in a single simulation run since it is in time-domain method. The time-dependent Maxwell's equations are discretized using central-difference approximations to the space and time. The resulting finite-difference equations are solved using software in a leapfrog manner: The electric field vector components in a volume of space are solved at a given instant in time and then the magnetic field vector components in the same spatial volume and the process is repeated until the desired steady-state electromagnetic field behaviour is obtained.

The increase of computer visualization capabilities influences numerical techniques. The FDTD method has particular advantage since it generate time-marched arrays of field quantities suitable for use in colour videos to illustrate the field dynamics. Since parallel-processing computer architectures have come to dominate supercomputing, numerical methods become easier. Computation FDTD has high efficiency on parallelprocessing CPU-based computers.

The maximum power output from a mobile phone is regulated by the mobile phone standard and by the regulatory agencies in each country. The SAR limit permitted over a volume of 1 gram of tissue is fixed as 1.6 $\mathrm{W} / \mathrm{kg}$, in India.

In this paper we tried to determine the Specific Absorption Rate (SAR) on human head tissues exposed to radiation between the frequency of $900 \mathrm{MHz}$ and $1800 \mathrm{MHz}$, since those are the typical frequencies for mobile communications systems. In order to determine the SAR, we used simulation of EMR using FDTD [1-8] method. The paper is outlined as follows: The basic theory of the method of FDTD included in section 2. Results obtained and the discussions of the result are detailed in section 3 . And section 4 includes conclusion and scope of further work. 


\section{METHODS}

\section{A. Electromagnetic waves}

The electromagnetic radiation is a form of energy made of electric and magnetic field varying in both time and space. These electromagnetic waves are plane waves or linearly polarized. Combination of two linearly polarized wave will lead to circularly polarized (if amplitudes are same) or elliptically polarized (if amplitudes are different)

Coupled Electric and magnetic field obeys wave equation, electromagnetic radiation are transmitted in air/vaccum with a velocity c (velocity of light)

$\mathrm{c}=\frac{1}{\sqrt{\varepsilon_{0} \mu_{0}}}$

The relation ship between Electric field and magnetic field can be written as

$\mathrm{E}=\mathrm{cB}$

The energy density of an electric field is

$W_{e}=\frac{1}{2} \varepsilon_{0} E^{2}$

Similarly the energy density of magnetic field is

$W_{m}=\frac{1}{2 \mu_{0}} B^{2}$

From Eqns (1), (2), (3) and (4) Energy density for magnetic field is

$W_{m}=W_{e}=\frac{1}{2} \varepsilon_{0} E^{2}$

and total energy density is

$W=W_{m}+W_{e}=\varepsilon_{0} E^{2}$

\section{B. Specific Absorption Rate(SAR)}

SAR is used as a measure of absorption of non ionizing electromagnetic radiation which is defined as ratio of absorbed power $\mathrm{P}$ per unit mass or ratio of energy absorbed per unit time

$S A R=\frac{P}{m} \mathrm{~W} / \mathrm{Kg}$

in terms of electric field,

$S A R=\frac{\sigma E^{2}}{\rho}$

where $\sigma$ is the specific conductivity of the tissue and $\rho$ is the density of the tissue. For a homogeneous medium with specific heat under constant pressure $c_{p}$,

$S A R=c_{p} \frac{\delta T}{\delta t}$
In solid and liquid there is no volume change due to increase in temperature therefore $c_{p}=c_{v}=c$ then

$S A R=c \frac{\delta T}{\delta t}$

\section{Maxwell Equations}

As per Maxwell's equation all electromagnetic phenomena can be expressed in terms of a coupled system of partial differential equations. Maxwell's equations as given below

$$
\begin{array}{llr}
\nabla \times \overline{\mathrm{E}}=-\frac{\partial \overline{\mathrm{B}}}{\partial \mathrm{t}} & \text { (11a) } & \nabla \times \overline{\mathrm{H}}=\frac{\partial \overline{\mathrm{D}}}{\partial \mathrm{t}}+\overline{\mathrm{J}}_{\mathrm{c}} \\
\nabla . \overline{\mathrm{D}}=0 & \text { (11c) } & \nabla \cdot \overline{\mathrm{B}}=0
\end{array}
$$

(11a) and (11b) can be rewritten as:

$\frac{\partial \overline{\mathrm{H}}}{\partial \mathrm{t}}=-\frac{1}{\mu} \nabla \times \overline{\mathrm{E}} \quad$ (12a) $\quad \frac{\partial \overline{\mathrm{E}}}{\partial \mathrm{t}}=\frac{1}{\varepsilon} \nabla \times \overline{\mathrm{H}}-\frac{\sigma}{\varepsilon} \overline{\mathrm{E}}$

It is seen that the time derivative of the E field is related to the curl of the $\mathrm{H}$ field while examining the Maxwell's curl equation. Thus the temporal rate of change in the $\mathrm{E}$ field is related to the spatial rate of change of the $\mathrm{H}$ field. Eqn (12a) can be written as

$\frac{\partial}{\partial t}\left(H_{x} \hat{a}_{x}+H_{y} \hat{a}_{y}+H_{z} \hat{a}_{z}\right)=-\frac{1}{\mu}\left|\begin{array}{ccc}\hat{a}_{x} & \hat{a}_{y} & \hat{a}_{z} \\ \frac{\partial}{\partial x} & \frac{\partial}{\partial y} & \frac{\partial}{\partial z} \\ E_{x} & E_{y} & E_{z}\end{array}\right|$

A similar equation can be defined for (12b) as well, and after equating $x, y$ and $z$ components on both sides of (12a) and (12b), the following scalar equation set is obtained

$\frac{\partial \mathrm{H}_{\mathrm{x}}}{\partial \mathrm{t}}=\frac{1}{\mu}\left(\frac{\partial \mathrm{E}_{\mathrm{y}}}{\partial \mathrm{z}}-\frac{\partial \mathrm{E}_{\mathrm{z}}}{\partial \mathrm{y}}\right)$

$\frac{\partial \mathrm{H}_{\mathrm{y}}}{\partial \mathrm{t}}=\frac{1}{\mu}\left(\frac{\partial \mathrm{E}_{\mathrm{z}}}{\partial \mathrm{x}}-\frac{\partial \mathrm{E}_{\mathrm{x}}}{\partial \mathrm{z}}\right)$

$\frac{\partial \mathrm{H}_{\mathrm{z}}}{\partial \mathrm{t}}=\frac{1}{\mu}\left(\frac{\partial \mathrm{E}_{\mathrm{x}}}{\partial \mathrm{y}}-\frac{\partial \mathrm{E}_{\mathrm{y}}}{\partial \mathrm{x}}\right)$

$\frac{\partial \mathrm{E}_{\mathrm{X}}}{\partial \mathrm{t}}=\frac{1}{\varepsilon}\left(\frac{\partial \mathrm{H}_{\mathrm{z}}}{\partial \mathrm{y}}-\frac{\partial \mathrm{H}_{\mathrm{y}}}{\partial \mathrm{z}}-\sigma \mathrm{E}_{\mathrm{x}}\right)$

$\frac{\partial \mathrm{E}_{\mathrm{y}}}{\partial \mathrm{t}}=\frac{1}{\varepsilon}\left(\frac{\partial \mathrm{H}_{\mathrm{x}}}{\partial \mathrm{z}}-\frac{\partial \mathrm{H}_{\mathrm{z}}}{\partial \mathrm{x}}-\sigma \mathrm{E}_{\mathrm{y}}\right)$

$\frac{\partial \mathrm{E}_{\mathrm{z}}}{\partial \mathrm{t}}=\frac{1}{\varepsilon}\left(\frac{\partial \mathrm{H}_{\mathrm{y}}}{\partial \mathrm{x}}-\frac{\partial \mathrm{H}_{\mathrm{x}}}{\partial \mathrm{y}}-\sigma \mathrm{E}_{\mathrm{z}}\right)$

\section{Finite Difference Time Domain (FDTD) Method}

The magnitude of the fields in EMR can be calculated by discretizing the Maxwell's equation with central difference approximation. K.Yee proposed this method. By the finite difference approximation, A new value of the $\mathrm{E}$ field is expressed in terms of the old value of the E field and the spatial partial derivatives of the old value of the $\mathrm{H}$ field. Thus the field components are calculated iteratively by marching-on in time. Similarly magnitude of $\mathrm{H}$ field also can be calculated iteratively by finite difference method. This forms coupled system of difference equations which can be solved in a leap-frog manner. 
The expression to calculate derivative by using finite difference expression using central difference formula is as follows

$\left.\frac{d}{d x} f(x)\right|_{x=x_{0}}=\frac{f\left(x_{0}+h\right)-f\left(x_{0}-h\right)}{2 h}$

Using this formula the derivative $\frac{\partial \mathrm{E}_{\mathrm{x}}}{\partial \mathrm{t}}$ of field $\mathrm{E}$ in in 1D (one dimensional) can be written as

$\frac{E_{x}^{n+\frac{1}{2}}(i)-E_{x}^{n-\frac{1}{2}}(i)}{\Delta t}$

The increment in time domain is fixed as $\Delta \mathrm{t}$ and assumed that the magnitude $\mathrm{E}_{\mathrm{x}}^{\mathrm{n}}$ is located at the center of the cell. Similarly $\frac{\partial \mathrm{E}_{\mathrm{x}}}{\partial \mathrm{t}}$ can be written in $3 \mathrm{D}$ as

$\frac{\left.E_{x}\right|^{n+\frac{1}{2}}{ }_{i+\frac{1}{2}, j, k}-\left.E_{x}\right|^{n-\frac{1}{2}}{ }_{i+\frac{1}{2}, j, k}}{\Delta t}$

\section{E. The Yee Algorithm}

The Maxwell's equations is discretized both in time and space with central difference approximations. A special notation introduced by Yee (involving superscripts and subscripts) is used, as explained below. The notation $(\mathrm{i}, \mathrm{j}, \mathrm{k}$ ) is used for integers, $(\Delta x, \Delta y, \Delta z)$ for space increments in the $\mathrm{x}, \mathrm{y}$, and $\mathrm{z}$ directions and any field component $\mathrm{A}$ is represented as $A^{n}{ }_{i, j, k}=A(i \Delta x, j \Delta y, k \Delta z, n \Delta t)$. Consider the first expression in Eqn (14)

$\frac{\partial \mathrm{H}_{\mathrm{x}}}{\partial \mathrm{t}}=\frac{1}{\mu}\left(\frac{\partial \mathrm{E}_{\mathrm{y}}}{\partial \mathrm{z}}-\frac{\partial \mathrm{E}_{\mathrm{z}}}{\partial \mathrm{y}}\right)$ can be expanded in time derivative

form as

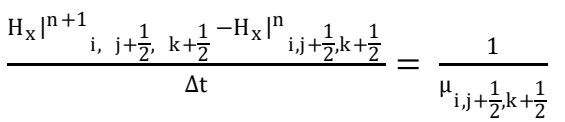

$$
\begin{aligned}
& {\left[\frac{\left.\mathrm{E}_{\mathrm{y}}\right|^{\mathrm{n}+\frac{1}{2}}{ }_{\mathrm{i}, \mathrm{j}+\frac{1}{2}, \mathrm{k}+1}-\left.\mathrm{E}_{\mathrm{y}}\right|^{\mathrm{n}+\frac{1}{2}}{ }_{\mathrm{i}, \mathrm{j}+\frac{1}{2}, \mathrm{k}}}{\Delta \mathrm{z}}-\frac{\left.\mathrm{E}_{\mathrm{z}}\right|^{\mathrm{n}+\frac{1}{2}}{ }_{\mathrm{i}, \mathrm{j}+1, \mathrm{k}+\frac{1}{2}}-\left.\mathrm{E}_{\mathrm{z}}\right|^{\mathrm{n}+\frac{1}{2}}{ }_{\mathrm{i}, \mathrm{j}, \mathrm{k}+\frac{1}{2}}}{\Delta \mathrm{y}}\right]}
\end{aligned}
$$

In similar manner we can derive expressions for $\left.\mathrm{H}_{\mathrm{y}}\right|^{\mathrm{n}+1} \mathrm{i}+\frac{1}{2} \mathrm{j}, \mathrm{k}+\frac{1}{2}$ and $\left.\mathrm{H}_{\mathrm{z}}\right|^{\mathrm{n}+1} \mathrm{i}+\frac{1}{2}, \mathrm{j}+\frac{1}{2}, \mathrm{k}$

Similarly the time derivative of the fourth expression from Eqn (14)

$$
\frac{\partial \mathrm{E}_{\mathrm{x}}}{\partial \mathrm{t}}=\frac{1}{\varepsilon}\left(\frac{\partial \mathrm{H}_{\mathrm{z}}}{\partial \mathrm{y}}-\frac{\partial \mathrm{H}_{\mathrm{y}}}{\partial \mathrm{z}}-\sigma \mathrm{E}_{\mathrm{x}}\right)
$$

can be written as

$$
\begin{aligned}
& \frac{\left.E_{x}\right|^{n+\frac{1}{2}}{ }_{i+\frac{1}{2}, j, k}-\left.E_{x}\right|^{n-\frac{1}{2}}{ }_{i+\frac{1}{2}, j, k}}{\Delta t}=\frac{1}{\varepsilon_{i+\frac{1}{2}, j, k}}\left[\frac{\left.H_{z}\right|^{n}{ }_{i+\frac{1}{2}, j+\frac{1}{2}, k}-\left.H_{z}\right|^{n}{ }_{i+\frac{1}{2}, j-\frac{1}{2}, k}}{\Delta y}-\right.
\end{aligned}
$$

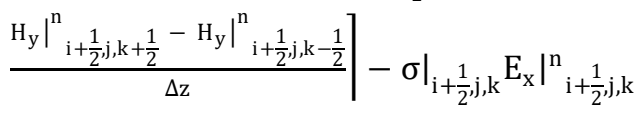

Similarly $\left.\mathrm{E}_{\mathrm{y}}\right|^{\mathrm{n}+\frac{1}{2}}{ }_{\mathrm{i}, \mathrm{j}+\frac{1}{2}, \mathrm{k}}$ and $\left.\mathrm{E}_{\mathrm{z}}\right|^{\mathrm{n}+\frac{1}{2}}{ }_{\mathrm{i}, \mathrm{j}, \mathrm{k}+\frac{1}{2}}$ can be derived.

As per these expressions, the field components are staggered in space and time. That is, the electric and magnetic field components are defined at different space points and different time instants. This can be graphically represente as edges of a cube called Yee Cell (Fig-1).Yee cell is the building block of the FDTD grid. As shown below, every E component is surrounded by four circulating $\mathrm{H}$ components, and every $\mathrm{H}$ component is surrounded by four circulating $\mathrm{E}$ components. If the front face is considered in particular, $\mathrm{H}_{\mathrm{x}}$ is expressed in terms of the $\mathrm{E}_{\mathrm{z}}$ values at the left and right and $E_{y}$ values at above and below. The cell-size $\Delta z$ is chosen with respect to the minimum wavelength in the simulation, otherwise all other frequencies will be filtered by mesh. The material bodies inside the area can be specified by constitutive relations at each point. The material may be air (vaccum), conducting metal (PEC), insulators and any anisotropic or bianisotropic materials

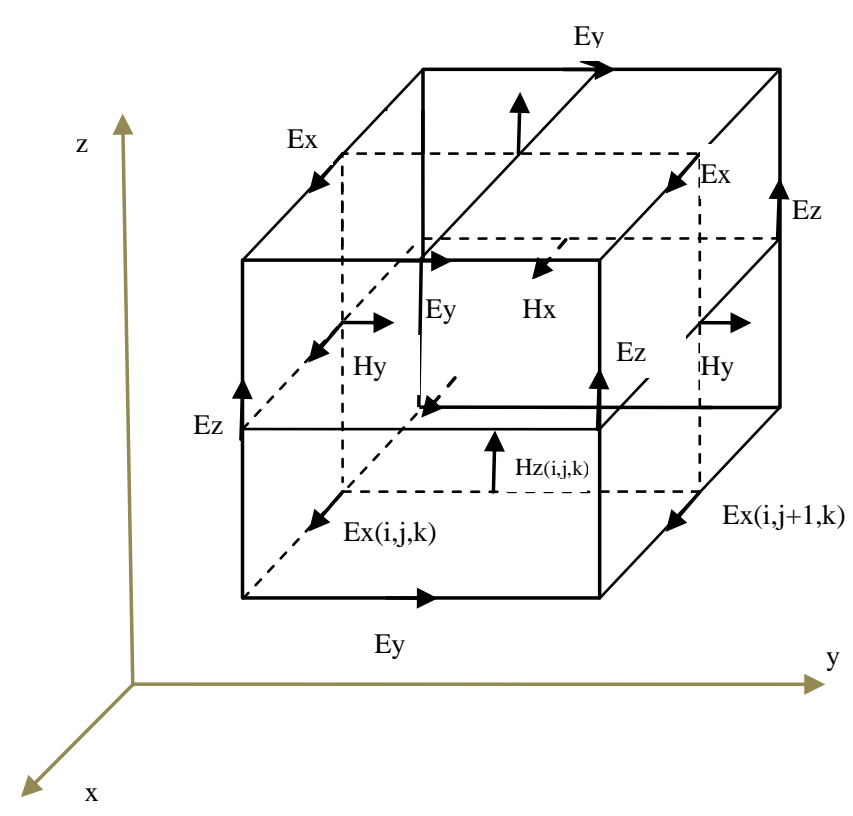

Fig-1 Yee Cell

The six spatio-temporal difference equations relating the field components are given below 


$$
\begin{aligned}
& \left.\mathrm{H}_{\mathrm{x}}\right|_{\mathrm{i}, \mathrm{j}+\frac{1}{2}, \mathrm{k}+\frac{1}{2}} ^{\mathrm{n}+1}= \\
& \left.H_{x}\right|_{i, j+\frac{1}{2}, k+\frac{1}{2}} ^{n}+\frac{\Delta t}{\mu_{i, j+\frac{1}{2}, k+\frac{1}{2}}}\left[\frac{\left.E_{y}\right|^{n+\frac{1}{2}}{ }_{i, j+\frac{1}{2}, k+1}-\left.E_{y}\right|^{n+\frac{1}{2}}{ }_{i, j+\frac{1}{2}, k}}{\Delta z}-\right. \\
& \left.\frac{\left.\mathrm{E}_{\mathrm{z}}\right|^{\mathrm{n}+\frac{1}{2}}{ }_{\mathrm{i}, \mathrm{j}+1, \mathrm{k}+\frac{1}{2}}-\left.\mathrm{E}_{\mathrm{z}}\right|^{\mathrm{n}+\frac{1}{2}} \mathrm{i,j, \textrm {k } + \frac { 1 } { 2 }}}{\Delta \mathrm{y}}\right]
\end{aligned}
$$

$\left.\mathrm{H}_{\mathrm{y}}\right|^{\mathrm{n}+1} \mathrm{i}+\frac{1}{2} \mathrm{j}, \mathrm{k}+\frac{1}{2}=$

$\left.\mathrm{H}_{\mathrm{y}}\right|_{\mathrm{i}+\frac{1}{2} \mathrm{j}, \mathrm{k}+\frac{1}{2}} ^{\mathrm{n}}+\frac{\Delta \mathrm{t}}{\mu_{\mathrm{i}+\frac{1}{2}, \mathrm{j}, \mathrm{k}+\frac{1}{2}}}\left[\frac{\left.\mathrm{E}_{\mathrm{z}}\right|^{\mathrm{n}+\frac{1}{2}} \mathrm{i+1,j, \textrm {k } + \frac { 1 } { 2 }}-\left.\mathrm{E}_{\mathrm{z}}\right|^{\mathrm{n}+\frac{1}{2}}{ }_{\mathrm{i}, \mathrm{j}, \mathrm{k}++\frac{1}{2}}}{\Delta \mathrm{x}}-\right.$

$$
\left.\frac{\left.E_{x}\right|^{n+\frac{1}{2}}{ }_{i+\frac{1}{2}, j, k+1}-\left.E_{X}\right|^{n+\frac{1}{2}}{ }_{i+\frac{1}{2}, j, k}}{\Delta z}\right]
$$

$\left.\mathrm{H}_{\mathrm{z}}\right|_{\mathrm{i}+\frac{1}{2}, \mathrm{j}+\frac{1}{2}, \mathrm{k}} ^{\mathrm{n}}=$

$\left.H_{z}\right|_{i+\frac{1}{2}, j+\frac{1}{2}, k} ^{n}+\frac{\Delta t}{\mu_{i+\frac{1}{2}, j+\frac{1}{2}, k}}\left[\frac{\left.E_{X}\right|^{n+\frac{1}{2}}{ }_{i+\frac{1}{2}, j+1, k}-\left.E_{X}\right|^{n+\frac{1}{2}}{ }_{i+\frac{1}{2}, j, k}}{\Delta y}-\right.$

$$
\left.\frac{\left.E_{y}\right|^{n+\frac{1}{2}}{ }_{i+1, j+\frac{1}{2}, k}-\left.E_{y}\right|^{n+\frac{1}{2}}{ }_{i, j+\frac{1}{2}, k}}{\Delta x}\right]
$$

$$
\begin{aligned}
& \left.E_{x}\right|^{n+\frac{1}{2}}{ }_{i+\frac{1}{2}, j, k}= \\
& =\left.E_{x}\right|^{n-\frac{1}{2}}{ }_{i+\frac{1}{2}, j, k}\left[\frac{2 \varepsilon-\sigma \Delta t}{2 \varepsilon+\sigma \Delta t}\right]+
\end{aligned}
$$

$$
\begin{array}{r}
{\left[\frac{2 \Delta \mathrm{t}}{2 \varepsilon+\sigma \Delta t}\right]\left[\frac{\left.\mathrm{H}_{\mathrm{Z}}\right|^{\mathrm{n}}{ }_{\mathrm{i}+\frac{1}{2}, \mathrm{j}+\frac{1}{2}, \mathrm{k}}-\left.\mathrm{H}_{\mathrm{z}}\right|^{\mathrm{n}}{ }_{\mathrm{i}+\frac{1}{2}, \mathrm{j}-\frac{1}{2}, \mathrm{k}}}{\Delta \mathrm{y}}-\right.} \\
\left.\frac{\left.\mathrm{H}_{\mathrm{y}}\right|^{\mathrm{n}}{ }_{\mathrm{i}+\frac{1}{2} \mathrm{j}, \mathrm{k}+\frac{1}{2}}-\left.\mathrm{H}_{\mathrm{y}}\right|^{\mathrm{n}}{ }_{\mathrm{i}+\frac{1}{2}, \mathrm{j}, \mathrm{k}-\frac{1}{2}}}{\Delta \mathrm{z}}\right]
\end{array}
$$

$\left.\mathrm{E}_{\mathrm{y}}\right|^{\mathrm{n}+\frac{1}{2}}{ }_{\mathrm{i}, \mathrm{j}+\frac{1}{2}, \mathrm{k}}=$

$=\left.E_{y}\right|_{i, j+\frac{1}{2}, k} ^{n-\frac{1}{2}}\left[\frac{2 \varepsilon-\sigma \Delta t}{2 \varepsilon+\sigma \Delta t}\right]+$

$$
\begin{aligned}
& {\left[\frac{2 \Delta \mathrm{t}}{2 \varepsilon+\sigma \Delta \mathrm{t}}\right]\left[\frac{\left.\mathrm{H}_{\mathrm{X}}\right|^{\mathrm{n}}{ }_{\mathrm{i}, \mathrm{j}+\frac{1}{2}, \mathrm{k}+\frac{1}{2},}-\left.\mathrm{H}_{\mathrm{X}}\right|^{\mathrm{n}}{ }_{\mathrm{i}, \mathrm{j}+\frac{1}{2}, \mathrm{k}-\frac{1}{2},}}{\Delta \mathrm{z}}-\right.} \\
& \left.\frac{\left.\mathrm{H}_{\mathrm{z}}\right|_{\mathrm{i}+\frac{1}{2}, \mathrm{j}+\frac{1}{2}, \mathrm{k}} ^{\mathrm{n}}-\left.\mathrm{H}_{\mathrm{y}}\right|_{\mathrm{i}-\frac{1}{2}, \mathrm{j}+\frac{1}{2}, \mathrm{k}} ^{\mathrm{n}}}{\Delta \mathrm{x}}\right]
\end{aligned}
$$

$$
\begin{aligned}
& \left.\mathrm{E}_{\mathrm{z}}\right|^{\mathrm{n}+\frac{1}{2}} \mathrm{i,j, \textrm {k } + \frac { 1 } { 2 }}= \\
& \mathrm{E}_{\mathrm{z}} \mathrm{I}^{\mathrm{n}-\frac{1}{2}}{ }_{\mathrm{i}, \mathrm{j}, \mathrm{k}+\frac{1}{2}}\left[\frac{2 \varepsilon-\sigma \Delta \mathrm{t}}{2 \varepsilon+\sigma \Delta t}\right]+
\end{aligned}
$$

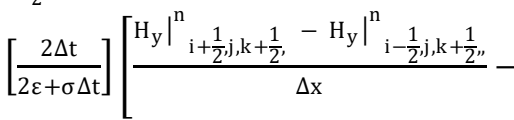

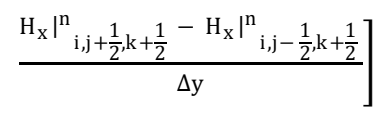

Once the computational domain is established, sources must be specified according to the type of excitation to be modelled. The source can be plane wave, a current on a wire, or an electric field between metal bodies.

\section{E. Source Signals}

The selection of source signal is also important since it represents the antenna used in mobile phone. Commonly used source signals are the sinusoidal signal or the Gaussian pulse. A modulated signal has to be used in order to avoid occurrence of high frequency at the beginning of the simulation. A spectrum of a Gaussian pulse is, also Gaussian with infinite frequencies. In this case, we should choose the cell size according to the maximum frequency of interest.

\section{F. Boundary Conditions}

We cannot simulate the propagation of the signal indefinitely, and we need to terminate the simulation in the FDTD grid. This is done by defining Absorbing Boundary Conditions (ABCs) over the outer boundary as desired. Another method is the Perfectly Matched Layer (PML) approach, which is a material layer absorbs electromagnetic waves without any reflection.

\section{G.Stability Condition for the FDTD Equations}

The spatio-temporal discretization of Maxwell's curl equations leads to a coupled system of difference equations. The solution of these equations is obtained iteratively starting from the initial condition. The system with difference equation is said to be stable if the solution stays bounded for all time instants. The stability condition, the relationship between space and time increments, is given by Courant stability Criteria. To ensure the stability of FDTD analysis, time step must be limited by the equation given below (as per Courant stability Criteria)

$\Delta \mathrm{t} \leq \frac{1}{\mathrm{c} \sqrt{\frac{1}{(\Delta \mathrm{x})^{2}}+\frac{1}{(\Delta \mathrm{y})^{2}}+\frac{1}{(\Delta \mathrm{z})^{2}}}}$

Let $\Delta \mathrm{x}=\Delta \mathrm{y}=\Delta \mathrm{z}=\Delta$ then

$\Delta \mathrm{t} \leq \frac{\Delta}{\mathrm{c} \sqrt{3}}$

From the converged solutions of FDTD expressions, the local SAR at $(\mathrm{i}, \mathrm{j}, \mathrm{k})^{\text {th }}$ cell inside the head is obtained using the following equation

$\operatorname{SAR}(\mathrm{i}, \mathrm{j}, \mathrm{k})=\frac{\sigma(\mathrm{i}, \mathrm{j}, \mathrm{k})|\mathrm{E}(\mathrm{i}, \mathrm{j}, \mathrm{k})|^{2}}{2 \rho(\mathrm{i}, \mathrm{j}, \mathrm{k})} \mathrm{W} / \mathrm{Kg}$

where, $\mathrm{E}$ is the r.m.s value of the electric field in $\mathrm{V} / \mathrm{m}, \sigma$ is the conductivity of the head in $\mathrm{S} / \mathrm{m}$ and $\rho$ is the mass density of the head in $\mathrm{Kg} / \mathrm{m}^{3}$. Maximum local $\mathrm{SAR}$ is obtained by finding the maximum value of $\operatorname{SAR}(\mathrm{i}, \mathrm{j}, \mathrm{k})$ for the whole head model at each frequency and the location of 
maximum local SAR may or may not be same for different frequencies.

\section{RESULTS}

\section{H. Simulation using FDTD}

Here the simulation of FDTD method is done in 3D which is more complex due to the fact that all vector field components $\left(E_{x}, E_{y}, E_{z}, H_{x}, H_{y}, H_{z}\right)$ are non-zero in general and each component is a function of three coordinate variables. The computational domain is a cube with side length $3 \mathrm{~cm}$ and size of cell is $\frac{\lambda}{10}$. Computation domain is fixed as cube of $3 \mathrm{X} 3 \mathrm{X} 3 \mathrm{~cm}$ with cell size as $0.033 \mathrm{~cm}(\Delta \mathrm{x}=$ $\Delta \mathrm{y}=\Delta \mathrm{z}=0.033 \mathrm{~cm})$, which means that there are $91 \mathrm{x} 91 \mathrm{x} 91$ $=753571$ Yee cells in the grid. The time increment satisfies $\Delta t=\frac{\Delta x}{2 c_{0}}$. The source of excitation is selected as sinusoidal pulse and kept at $0.375 \mathrm{~cm}$ away from the corner. This is to generate a electromagnetic radiation similar to that generated by keeping a mobile phone near the ear. The PML approach is used as boundary condition. The figure 2 shows the radiation pattern obtained for $900 \mathrm{MHz}$ during an instant of time (at time step 170).

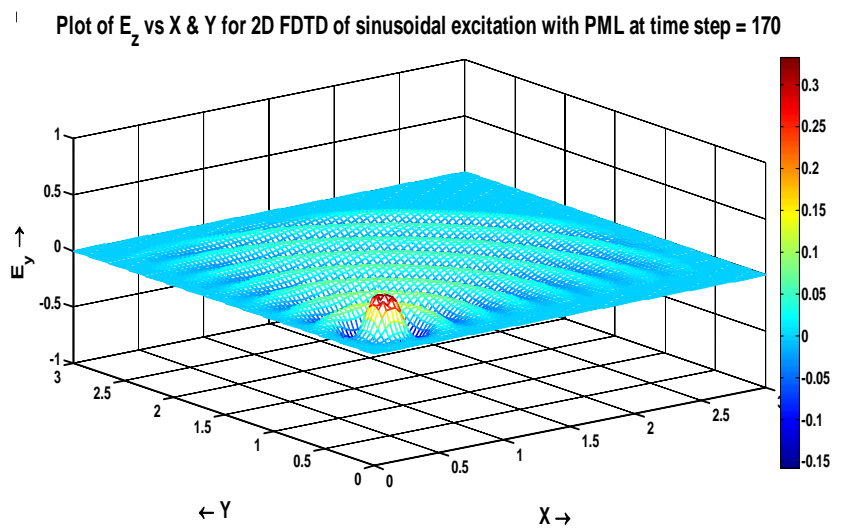

Fig 2. Snap shot of $E_{z}$ over $x-y$ plane at time $=170$

\section{Calculation of $S A R$}

To obtain electric field E a sinusoidal pulse of unit amplitude is used as source of excitation. The equivalent antenna input impedance is $50 \Omega$. And input power of mobile phone is 0.6 watts. The value of SAR is calculated using the formula (23) given below

$$
\begin{aligned}
& \operatorname{SAR}(\mathrm{i}, \mathrm{j}, \mathrm{k})=\frac{\sigma(\mathrm{i}, \mathrm{j}, \mathrm{k})|\mathrm{E}(\mathrm{i}, \mathrm{j}, \mathrm{k})|^{2}}{2 \rho(\mathrm{i}, \mathrm{j}, \mathrm{k})} \mathrm{W} / \mathrm{Kg} \\
& =\frac{\sigma(\mathrm{i}, \mathrm{j}, \mathrm{k})\left\{\left|\mathrm{E}_{\mathrm{x}}(\mathrm{i}, \mathrm{j}, \mathrm{k})\right|^{2}+\left|\mathrm{E}_{\mathrm{y}}(\mathrm{i}, \mathrm{j}, \mathrm{k})\right|^{2}+\left|\mathrm{E}_{\mathrm{z}}(\mathrm{i}, \mathrm{j}, \mathrm{k})\right|^{2}\right\}}{2 \rho(\mathrm{i}, \mathrm{j}, \mathrm{k})} \mathrm{W} / \mathrm{Kg}
\end{aligned}
$$

The simulation is performed for the frequencies of 900 $\mathrm{MHz}$ to $1800 \mathrm{MHz}$, since those are the typical maximum and minimum value of frequencies for mobile phone communications. The values for the different parameters needed to calculate SAR are presented in Table- 1 and Table-2.

Table 1. Electromagnetic properties for humn head tissues at $900 \mathrm{MHz}$

\begin{tabular}{|l|l|l|l|}
\hline Tissue & \multicolumn{1}{|c}{$\boldsymbol{\varepsilon}_{\mathbf{r}}$} & $\boldsymbol{\sigma}(\mathrm{S} / \mathrm{m})$ & $\boldsymbol{\rho}(\mathrm{Kg} / \mathrm{m} 3)$ \\
\hline Skin/Fat & 23.000 & 0.630 & 1.000 \\
\hline Muscle & 59.000 & 1.260 & 1.000 \\
\hline Bone & 5.4000 & 0.045 & 1.200 \\
\hline Brain & 51.000 & 1.460 & 1.050 \\
\hline
\end{tabular}

Table 2. Electromagnetic properties for humn head tissues at $1800 \mathrm{MHz}$

\begin{tabular}{|l|l|l|l|}
\hline Tissue & \multicolumn{1}{|c|}{$\boldsymbol{\varepsilon}_{\mathrm{r}}$} & $\boldsymbol{\sigma}(\mathbf{S} / \mathbf{m})$ & $\boldsymbol{\rho}(\mathbf{K g} / \mathbf{m} \mathbf{3})$ \\
\hline Skin/Fat & 38.870 & 1.190 & 1.000 \\
\hline Muscle & 59.370 & 2.040 & 1.000 \\
\hline Bone & 11.500 & 0.230 & 1.200 \\
\hline Brain & 43.540 & 1.150 & 1.050 \\
\hline
\end{tabular}

Value of SAR is calculated using the simulated value of electric field at $900 \mathrm{MHz}$ and $1800 \mathrm{MHz}$ using two powers of excitation of $0.6 \mathrm{~W}$ and $1.2 \mathrm{~W}$ ( Table 3). Maximum value of Electric field is used for the calculation of SAR. All the values of SAR obtained are within the prescribed limit by the regulating authority. As per regulations the value allowed for head is 2 by ICNIRP and 1.6 by IEEE. The value of SAR obtained for both frequencies $(900 \mathrm{MHz}$ and $1800 \mathrm{MHz}$ ) are less than $1.6 \mathrm{~W} / \mathrm{Kg}$

Table 3. SAR in W/Kg calculated from the simulated value of Elecric field for $900 \mathrm{MHz}$ and $1800 \mathrm{MHz}$

\begin{tabular}{|l|r|r|r|r|}
\hline & \multicolumn{2}{|c|}{ 900MHz } & \multicolumn{2}{c|}{$\mathbf{1 8 0 0 M H z}$} \\
\hline Tissue & \multicolumn{1}{|c|}{$\mathbf{0 . 6 W}$} & \multicolumn{1}{c|}{$\mathbf{1 . 2 W}$} & $\mathbf{0 . 6} \mathbf{W}$ & \multicolumn{1}{c|}{$\mathbf{2 W}$} \\
\hline Skin/Fat & 0.106 & 0.423 & 0.195 & 0.779 \\
\hline Muscle & 0.211 & 0.846 & 0.334 & 1.335 \\
\hline Bone & 0.006 & 0.025 & 0.019 & 0.075 \\
\hline Brain & 0.147 & 0.588 & 0.183 & 0.731 \\
\hline
\end{tabular}

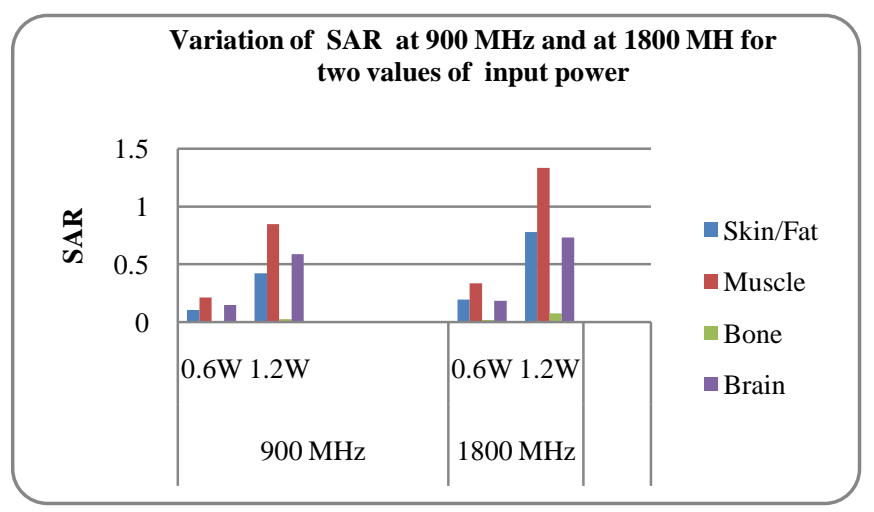

The two common international standards are ICNIRP and IEEE. ICNIRP is International Commission on NonIonizing Radiation and Protection (ICNIRP) 1998 having Guidelines for limiting the exposure to time-varying electric, magnetic, and electromagnetic fields (up to 300 GHz). The IEEE C95.1-1999 is Standard for safety levels 
with respect to human exposure to radio frequency electromagnetic fields, $3 \mathrm{kHz}$ to $300 \mathrm{GHz}$. Table 4 shows the basic SAR limits for both ICNIRP and IEEE standards.

Table 4. Basic SAR restrictions $(\mathrm{W} / \mathrm{Kg})$

\begin{tabular}{|l|l|l|l|}
\hline $\begin{array}{l}\text { Standard } \\
\text { type }\end{array}$ & $\begin{array}{l}\text { Frequency } \\
\text { range }\end{array}$ & $\begin{array}{l}\text { Whole } \\
\text { body }\end{array}$ & $\begin{array}{l}\text { Local SAR } \\
\text { (Head and } \\
\text { trunk) W/Kg }\end{array}$ \\
\hline ICNIRP & $\begin{array}{l}100 \mathrm{KHz}-10 \\
\mathrm{GHz}\end{array}$ & 0.08 & 2 \\
\hline IEEE & $\begin{array}{l}100 \mathrm{KHz}- \\
6 \mathrm{GHz}\end{array}$ & 0.08 & 1.6 \\
\hline
\end{tabular}

\section{CONCLUSION}

Muscle is more affected while increasing the power of excitation. The increase in SAR shows more radiation is absorbed this may cause temperature increase. This can increase or decrease the stress in muscles.

Earlier mobile phones were used for voice communication only, but since the arrival of the videophone, in spite of technological refinements SAR levels are on increase. The earth's natural electric and magnetic fields are static and seems as bio inactive. Week fields also have same behaviour. For frequencies below $10^{6} \mathrm{~Hz}$, two fields (electric and magnetic) are not connected and the intensities are measured separately. This is the reason for living organism are able to get adapted to week external stressors.

The mobile phone standard and the regulatory agencies in each country give guidelines about maximum power allowable for mobile phone and base station. But practically according to the reception quality and signal strength, the power level is increased or decreased automatically in mobile phone and the base station, within a certain span, to accommodate different situations like nearer or farther to the station. So there is a possibility to increase the power level beyond the specified limit, can produce high SAR, which is harmful to human beings.

SAR for the specified range of frequency for mobile phone communication is found within the specified limit insisted by ICNIRP/IEEE.

\section{REFERENCES}

[1]. Peter Stavroulakis ,'Biological Effects of Electromagnetic Fields: Mechanisms, Modeling , biological effects, Therapeutic effects, ISBN : 978-3540-42989-0 Springer 2003.

[2]. Qutob, S S,Chauhan.V, Bellier R.V, Yauk, C. L, Douglas G. R, Berndt L, Williams A, Gajda G B, Lemay, E, Thansandote A, McNamee, J. P," Microarray gene expression profiling of a human glioblastoma cell line exposed in vitro to a $1.9 \mathrm{GHz}$ pulse-modulated radiofrequency field", Journalof Radiation Research, vol.165, no.6, p.636-44, DOI: 10.1667/RR3561.1,2006
[3]. Nur A. Husni, Mohammad T. Islam, Mohammad R, Faruque, and Norbahiah Misran ," Effects of Electromagnetic Absorption towards Human Head due to variation of its dielectric Properties at 900,1800 and $1900 \mathrm{MHz}$ with Different Antenna Substrates"

Progress In Electromagnetics Research, Vol. 138, 367388, 2013

[4]. Stavros V. Georgakopoulos, Craig R. Birtcher, Constantine A. galanis, and Rosemary A. Renauf, "Higher-Order Finite-Difference Schemes for Electromagnetic Radiation, Scattering, and Penetration, Part I: Theory", Antenna's and Propagation Magazine, Vol. 44, No. 1, February 2002 pp134-142

[5]. Hesham Eldeeb, Hala Elsadek, Maha Dessokey, Haytham Abdullah, Nader Bagherzadeh, " High Performance Parallel Computing for FDTD Numerical Technique in Electromagnetic Calculations for SAR Distribution Inside Human Head", ISSN: 1792-4251 114 ISBN: 978-960-474-201-1, Latest Trends on Computers (Volume I)pp 114-120.

[6]. Selcuk Paker, Levent Sevgi, "FDTD Evaluation of the SAR Distribution in a Human Head Near a Mobile Cellular Phone", Elektrik, Vol.6, No.3, 1998

[7]. Levent Seyfi and Ercan Yaldiz,'Numerical Computing of Reduction of SAR Values in a Homogenous Head Model Using Copper Shield ", Proceedings of the World Congress on Engineering 2010 Vol II WCE 2010, June 30 - July 2, 2010, London, U.K.

[8]. Md. Faruk Ali, Sudhabindu Ray, "SAR Analysis in a Spherical Inhomogeneous Human Head Model Exposed to Radiating Dipole Antenna for $500 \mathrm{MHz}-3$ GHz Using FDTD method" , International Journal of Microwave and Optical Technology, Vol -4, No 1 January 2009

[9]. Santosh S. Mhaske, Prof. G. A. Kulkarni, Prof.Rahul L. Tayade, "SAR in Life Tissue at GSM Frequencies "International Journal of Advanced Research in Computer Science and Software Engineering, Volume 2, Issue 4, April 2012 ISSN: 2277 128X

[10].S. Khalatbari, D. Sardari, A. A. Mirzaee, and H. A. Sadafi,"Calculating SAR in Two Models of the Human Head Exposed to Mobile Phones Radiations at 900 and $1800 \mathrm{MHz}$, Progress In Electromagnetics Research Symposium 2006, Cambridge, USA, March 26-29

[11].Francisco Nabais Ferro, Guilherme Taveira Pinto, Pedro Pinho, "SAR calculation using FDTD simulations",Alicerces. 2009;II(2):17-25. 